\title{
THE STRONG SILENT TYPE: MASCULINITY AND WANDELWEISER MUSIC
}

\author{
Ed Cooper
}

\begin{abstract}
Masculinity is not just about being the loudest; it is a contradictory network of relationships relating to power, control and work. Deploying the methodology first developed in Raewyn Connell's Masculinities (1995), this article argues that Wandelweiser works exhibit masculine social ordering. Silence presents apparent creative agency which is ultimately governed by the composer; fragile timbres strain the bodies of both the performers and listeners and encourage constant labour; openness displaces authorship, leaving interpreters to fill a composershaped hole. Analysis of these facets reveals a top-down power dynamic from these composers of the quiet that is integrally related to Connell's conception of hegemonic masculinity: the composer encourages reproduction and questioning of their dominant role from interpreters, which, counterintuitively, implicates their position of power. This investigation is interwoven with diary entries exposing and critiquing my own compositional process, demonstrating how masculinity is performed throughout my creative process and its subsequent documentation. This article explores how subversive, even if invisible, elements of masculinity lie within the process and product of composing instrumental music that initially may seem to counter typical 'masculine' musics.
\end{abstract}

\section{Introduction}

Evening birdsong, distant road traffic and audience members' tentative movements form a tapestry of sound which breathes to fill a large, open space: a dilapidated church, an art gallery, a concert hall. Musicians are poised at the front of the room; softly illuminated by the long evening light, they flicker in and out of focus. Fragile but sustained tones, omitting any distinct rhythms, appear for what feels like a few minutes before halting and falling back into the busy silence from which they came. This process repeats several times, never unveiling anything more (or less) complex than the sounds themselves.

Such is the experience of the music of the Wandelweiser collective. Founded in 1992 by Antoine Beuger and Burkhard Schlothauer, its composers/performers create sonic works rooted in the ideas of 
John Cage. The title might awkwardly translate to 'change signpost' (Wegweiser des Wandels) or, as key member Michael Pisaro writes, it could gesture toward a 'weiser Mann des Wandels' (a wise man of change). ${ }^{1}$ Despite lacking an official, 'sanctioned' artistic statement, Wandelweiser's aesthetic vision revolves around interpretations of Cage's 4'33" (1952). Manfred Werder states that silence is used to develop novel relationships to 'the sounding world'; Pisaro notes the ways in which Cage's 'silent prayer' highlights the disparities between what a score notates and the sonic outcomes of its performance; Beuger seeks to view silence as an 'autonomous musical phenomenon'. ${ }^{2}$ These distinctions between readings of $4^{\prime} 33^{\prime \prime}$ nevertheless highlight certain commonalities within the collective: Cage's silent work can undermine social roles and relationships to create what G. Douglas Barrett calls 'post-4' $33^{\prime \prime}$ music'.

In practice, the music of Wandelweiser composers is often characterised by extended silences, highlighting the ambient sounds of a location, which are framed by quiet and often performatively ephemeral tones, at least as much as the ambient sounds frame the pitch materials which are performed. ${ }^{4}$ The scores frequently present a degree of openness, sometimes not specifying exact instrumentation, and often leaving interpreters to decide durations of events. Wandelweiser pieces seem alluring and distant, an invitation to listen to pre-existing phenomena framed by aurally pleasant instrumental sounds, for no other reason than what one might find in the experience of sound for its own sake. However, as Seth Kim-Cohen notes on Cage's adaptation of Eastern philosophy as a gateway to this apparently egoless engagement with sound: 'it, it turns out, is never simply it'.'

At a surface level, Wandelweiser works appear opposed to traditional understandings of masculinity. Their performance is relentlessly mellow. Quiet volumes require nuanced attention (and, too, attention to nuance) from both performers and audiences. However, as I propose in what follows, when analysed through the lens of masculinity as described in Raewyn Connell's pathbreaking Masculinities, these observations concerning the superficial Wandelweiser experience overlook the gendered power relations inherent in these works. Masculinity is not just about being loud or aggressive. Rather, it is a contradictory network of relationships relating to power, control, and work. Indeed, although there are female members of the collective, such as Eva-Maria Houben and Emmanuelle Waeckerlé, their presence does not contradict the points I mean to make here. I take it as axiomatic that gender cannot simply and unproblematically be mapped onto biological sex, that masculinity and femininity are not simply ways of describing traits an individual might exhibit by virtue of or despite biological predetermination. Rather, masculinity is a mode of organising and reproducing social practices, practices both implicating and performed by bodies, such as those of the creatively laboured performer or strained listener. $^{6}$

${ }^{1}$ Nicholas Melia and James Saunders, 'Introduction: What is Wandelweiser?', Contemporary Music Review 30/6 (2011), p. 445.

2 G. Douglas Barrett, 'The Silent Network: The Music of Wandelweiser', Contemporary Music Review 30/6 (2011), pp. 457-60.

3 Barrett, 'The Silent Network', p. 459.

4 Melia and Saunders, 'Introduction', p. 446.

5 Seth Kim-Cohen, In the Blink of an Ear: Towards a Non-Cochlear Sound Art (New York: Continuum, 2009), p. 151.

${ }^{6}$ Raewyn Connell, Masculinities, 2nd edn (Berkeley: University of California Press, 2005), p. 71. 
This article argues, following Connell, that in many respects the music of the Wandelweiser collective exhibits and implicitly promotes a masculine social ordering. Although these compositions may initially appear to diverge from the traditional master-servant relationship between composer and performer, through their use of silence, fragile timbres, and the openness of scores, the music is intimately reliant upon the cultivation of a particular form of tension in the listener and a highly specific type of labour on behalf of the interpreter (s), in ways which remain intertwined, if not complicit, with longstanding tropes of masculinity. Analysis of these facets reveals a topdown power dynamic from these composers of the quiet, integrally related to Connell's conception of hegemonic masculinity: composers may encourage reproduction and questioning of their dominant role from interpreters, but this, counterintuitively, reinforces their position of power. ${ }^{7}$ This investigation is interwoven with diary entries documenting my own process of composing a work for piano and cello. As a composer of music far from dissimilar to that of Wandelweiser composers, these diary entries serve to expose and criticise my practice with regard to the masculine social ordering analysed, demonstrating how masculinity is (inadvertently) performed throughout my compositional process.

Connell argues that 'the state', as an institution, is masculine and that, further, the state would continue to be so, regardless of the sex or gender of any of the office holders; the British state did not become any more feminine when Margaret Thatcher became Prime Minster, for example. ${ }^{8}$ Similarly, this essay is in no sense intended as an attack on the personalities of any individuals associated with Wandelweiser. To be clear, I am not implying that the discussed composers are violent, sexist or homophobic, or that they exhibit any other 'toxic male' traits. Rather, I am discussing the relations that their work provokes and propagates and how, through the lens of Connell, these are particularly masculine. The more superficial auditory characteristics of much of the music examined here suggests that, if anything, these sorts of underpinning masculinisms run counter to the likely (compositional) aims and interests of those involved. It is not least for this reason that I aim to implicate myself directly in what is outlined here. This attitude is reinforced through the exposure of my own practice: if anyone is personally critiqued throughout this article, that individual is me.

I started this piece with vague, lucid sentences concerning what I want it to 'do'. Essentially, it's an extension of my previous work, trying to offer no substantial points of stability to the performers or listeners; through setting up situations in which the movements towards something destabilises or undermines the very thing it is trying to get towards. Think of those optical illusions with lots of black squares separated regularly with white lines: one can see black dots flickering in the peripheral vision, but any attempt to bring them into focus removes them from sight.

\section{Use of Silence}

Perhaps the signature feature of Wandelweiser music is the use of extensive silence: works often contain more ambient than performed sounds. Michael Pisaro's Ascending Series (2.1) is an example of this structure (see Figure 1). Across a total duration of some 9 minutes

\footnotetext{
${ }^{7}$ Connell, Masculinities, p. 78.

${ }^{8}$ Connell, Masculinities, p. 73.
} 
Ascending Series (2) is to be played outdoors, along with a field recording, or a combination of both. The piece should be done more than once on a concert or installation.

The piece lasts 9'40". Performers will need stopwatches.

Large scale time division:

$\begin{array}{ll}0: 00 & \text { start / pause } \\ 0: 30 & \text { system 1 } \\ 1: 50 & \text { pause } \\ 2: 20 & \text { system 2 } \\ 3: 40 & \text { pause } \\ 4: 10 & \text { system } 3 \\ 5: 30 & \text { pause } \\ 6: 00 & \text { system 4 } \\ 7: 20 & \text { pause } \\ 7: 50 & \text { system 5 } \\ 9: 10 & \text { pause } \\ 9: 40 & \text { end }\end{array}$

Each system lasts 80 seconds. Within each system one instrument has a fixed part, labeled above the bottom staff (i.e., part number 5). This part, notated with whole notes, is played as four 10 second tones each followed by a 10 second silence.

Each of the other four musicians has a choice of what to do for the duration of a system.

a.) play one of the other parts (1-4), in the octave given. (Here as with part 5, each tone lasts 10 seconds and is followed by a 10 second silence.)

b.) sustain a tone very softly for a multiple of 20 seconds (up to the total duration of the 80 second system). This tone must begin with any of the tones in part 5 and must be one of the notes (in any octave) given in that system.

c.) play a long, soft, white noise at any time during the system (or more than once), modeling it, as best as one can, upon one of the noises one hears.

d.) play nothing.

Figure 1:

Performance notes for Michael Pisaro's Ascending Series (2.1) and 40 seconds, three minutes are marked as a 'pause' in which the five interpreters do not perform any sounds. Even within the 'active' sections, marked as 'system', only one of the performers is required to create any sounds: four ten-second tones divided up with an equal measure of silence. In short, this $9^{\prime} 40^{\prime \prime}$ piece may contain only $3^{\prime}$ $20^{\prime \prime}$ of performed sounds. Pisaro's output derives its character through its relative lack of performed sounds, as stressed by Jürg Frey when he argues that silence 'derives its power from the absence of the sounds we have just heard'. Indeed, it is notable that Frey is concerned with the power of silence.

Interweaving interviews with Beuger and Heideggerian thought, Nicholas Melia proposes that silences found in Cage's 4' $33^{\prime \prime}$ and, I suggest, the Wandelweiser context can be understood as an infinite dense continuum' deriving their dominance from omission. ${ }^{10}$ This

9 Jürg Frey, 'The Architecture of Silence', Wandelweiser, trans. Michael Pisaro (1998). www. wandelweiser.de/_juerg-frey/texts-e.html (para. 2 of 6).

${ }^{10}$ Nicholas Melia, 'Stille Musik: Wandelweiser and the Voices of Ontological Silence', Contemporary Music Review, 30/6 (2011), p. 488. 
realm of possibility and ambiguity poses questions to the listener: was that the end of the piece? What happens next? What should I be doing or listening to? Kim-Cohen's reading of Cage's $4^{\prime} 33^{\prime \prime}$ opines that these empty spaces destabilise the roles of and relationship between the performer and composer, allowing them to 'drift freely in the tides of conceptualization'. ${ }^{1}$

Although apparently suggesting a level playing field in which individuals are invited to rethink established hierarchies, silence is precisely framed as a space of reconfiguration controlled by the composer, a power structure that continues to resemble Connell's hegemonic masculinity. Dissenting individuals may have a degree of autonomy, but still within parameters that benefit the dominant group. ${ }^{12}$ Connell presents the example of the aftermath of the Stonewall Riots in 1968. Although the riots provided a form of challenge to hegemonic masculinity, Connell argues that, in the first place, the reconfigurations within gay communities which succeeded Stonewall actually loosened ties with likely allies amongst feminist communities, while patriarchal masculinity was able to appropriate and make 'safe' visible signifiers of gay subcultures, such as leather or BDSM fashions. ${ }^{13}$ The deployment of silence in the music of the Wandelweiser composers might, indeed, create a space in which it is possible to imagine new forms of equity, but the invitation to experience ambient sounds in this way is always at the behest of the composer, shoring up their dominant subject position. Relations might shift and flex between interpreters, but only to the degree allowed in advance by the composer.

Mention of Stonewall may cause one to think of broader histories of silence, silencing and the silenced, including its the deployment by composers. Jonathan Katz argues that Cage's preoccupation with silence is intertwined with his (largely closeted, publicly, at any rate) homosexuality. An engagement with Zen might be read, therefore, as a sort of remedy for his failed marriage to Xenia Kashevaroff, such that staying in the 'the closet' becomes coherent with a larger aesthetics of non-interference and detachment. ${ }^{14}$ Indeed, Katz suggests that, within the homophobic McCarthy era of 1950s New York, silence was not only an expression of Cage's identity but also a mode of active resistance: 'conversations' were favoured over 'communication', never imposing one object over another, thus moving towards the dismantling of traditional hierarchies of knowledge and the concert hall. ${ }^{15}$ Nevertheless, such deployment of silence was surely not just privative but also essentially private.

Despite an aesthetic derived from interpretations of Cage's silence, Wandelweiser music's inclusion of instrumental sections, even after significant silence, allows interpreters only to move towards 'resistance' when permitted to do so by the composer. Although these silences might have a queer origin, their function is not comparable: as Katz states, 'the goal [of Cage's silence] is not to challenge power but to escape it', which is simply not possible when the listener is confronted with recurring instrumental interludes. ${ }^{16}$ Instead, according to

\footnotetext{
11 Kim-Cohen, In the Blink of an Ear, p. 167.

12 Connell, Masculinities, p. 77

13 Connell, Masculinities, pp. 216-20.

14 Jonathan Katz, 'John Cage's Queer Silence; Or, How to Avoid Making Matters Worse', GLQ: A Journal of Lesbian and Gay Studies, $5 / 2$ (1999), p. 235.

15 Katz, 'John Cage's Queer Silence', pp. 239-40.

16 Katz, 'John Cage's Queer Silence', p. 248.
} 
Melia's article - and most of the edition of the Contemporary Music Review dedicated to Wandelweiser for that matter - the silence in Wandelweiser music is metaphysical in the function of its deployment, relating philosophy constructed by straight men of the twentieth century. ${ }^{17}$ This analytical and creative approach overlooks the ways in which individuals have previously identified with silence, which, according to Katz, is so crucial to its initial use. To repeat the comparison with Stonewall in fuller terms, one might read the music of the Wandelweiser composers as not only incorporating but also reappropriating the queerness of Cage's silence in a straight context, in the process perhaps blunting its radical potential, particularly through its validation from the canon of heterosexual philosophy. ${ }^{18}$

On Saturday, I argued with my partner. I made a nasty and utterly shameful comment about someone who they used to date, stormed off into the night, put up a worrying Instagram story, and then turned my phone off. After wandering Leeds for three hours, crying, talking out loud to myself, drinking, and lying down in the middle of quiet roads, I switched my phone back on to find missed calls from the police and countless other attempts to contact me. I don't think I've ever been so embarrassed in my life. Everyone knows what young men like me do when they vanish in a drunken stupor and send messages expressing how sorry they are. I actually don't know what possessed me to do it; I knew it would upset the people around me. I don't know if this affects my compositional process, but in the case that it does, it feels worthwhile to note.

It is not only creative roles that are blurred when interpreters are dropped into these deceptive moments of absence. According to Martina Viljoen, interpreters must determine musical meaning across this 'dynamic field of influence' found in silence through constantly reinterpreting performative frames to suit the unfolding piece. ${ }^{19}$ As Melia writes of Frey's use of silence, these moments 'derive their power from their correspondence to the absented sound ... rather than functioning autonomously'. ${ }^{20}$ Silence derives its masculine power through presenting a situation in which interpreters are momentarily invited to create meaning, only for this opportunity to be withdrawn and for the meaningfulness of the work to be more or less wholly separable from 'truly' meaningful silence; in an only slightly extended version of this argument, it does not matter what sort of meaning the interpreters create. Connell notes that abstract labour - work that requires no skill and can be done by anyone - is frequently exploited by the masculine hegemony and treats individuals as expendable: she notes the careers of many working-class men which consist of 'odd jobs' and physical labour. ${ }^{21}$ Similarly, Wandelweiser composers' use of silence subordinates the interpreters, dictating when (indeed how) they may create meaning, with any outcome of these actions strengthening the composer's dominant position.

\footnotetext{
17 Melia, 'Stille Musik', pp. 490-91.

18 Again, I neither know nor particularly care about the sexuality of any of the Wandelweiser composers. By suggesting that this deployment of silence is essentially a heterosexual one, I aim to insist on an analysis of what silence does and how it becomes meaningful, not that certain usages of silences are necessarily or even particularly revealing of anything about the individual deploying them. Additionally, I do not wish to dismiss all 'white straight male' philosophy; there are certainly large portions of it that can be very insightful in particular contexts.

19 Martina Viljoen, 'Questions of Musical Meaning: An Ideology-Critical Approach', International Review of the Aesthetics and Sociology of Music, 35/1 (2004), p. 21.

${ }^{20}$ Melia, 'Stille Musik', p. 479.

${ }^{21}$ Connell, Masculinities, pp. 95-8.
} 
Such anonymity can be paralleled with Marc Augé's 'non-places', areas that are not themselves meaningful but function as passageways between 'proper' places as result of supermodernity. ${ }^{22} \mathrm{He}$ argues that non-places have the ability to strip individuals of their individuality: for example, motorway services in the UK generally look the same, presenting identical, ephemeral images for the individual to consider the past or future, without relations 'making any sense', thus emptying them of their individuality. ${ }^{23}$ Similarly, Wandelweiser music insists that the listener passes through these silent 'non-places', requiring anonymous and inconsequential work to construct meanings, aligning itself with Connell's abstract labour. What's more, Tim Edwards notes that work plays a key role in the formation and maintenance of masculine identities: being 'successful' at work, regardless of the financial or social gain, equates to being 'masculine'. ${ }^{24}$ Through understanding the silences in Wandelweiser music as non-places defined by sameness of identity, interpreters must work overtime to be successful in creating (personal) meanings of the blank sonic canvas. Interpreters are invited to behave as (co-)composers but only within the parameters dictated by the 'real' composer, reproducing and thus reinforcing the masculine hegemony.

\section{Fragile Timbres}

Fragility in music is a nebulous term, only recently coming into focus as an analytical tool, rather than an evocative phrase. In his examination of Jakob Ullmann's work, Oliver Thurley argues:

A musical situation may be considered fragile if the normal functionality of a sound - or the means of its production - is somehow destabilised and placed at risk of collapse. Fragility, then, can be understood as a precarious state in which sound is rendered frangible and susceptible to being destroyed or disrupted. ${ }^{25}$

This definition need not be limited to the performers, as Thurley notes, but can be exploited in the experience of listening. Small sounds evade the listener's attention and require sustained focus to make sense of this fleeting soundscape. ${ }^{26}$ In his Streichquartett II Frey's single-minded use of half-harmonics creates a situation which can be considered fragile. ${ }^{27}$ The technique requires the performers to stop a string with their index finger and gently depress the same string, sometimes as little as a semi-tone higher. The result is a muffled sound presenting both tones clouded by high harmonics prone to collapsing. The performer is required to balance the pressure of the two fingers with machine-like precision, readjusting as the production of sound reveals the faltering success of their movements; Frey's explanatory video demonstrates the fragility of the technique. ${ }^{28}$

Subjecting the performers' bodies to these arduous actions can be paralleled with the social ordering of Connell's masculinities. ${ }^{29}$

22 Marc Augé, Non-Places: Introduction to an Anthropology of Supermodernity, trans. by John Howe (London: Verso, 1995), pp. 75-115.

23 Augé, Non-Places, p. 87

24 Tim Edwards, Cultures of Masculinity (Abingdon: Routledge, 2005), p. 8.

25 Oliver Thurley, 'Disappearing Sounds: Fragility in the Music of Jakob Ullmann', TEMPO, 69 , issue 274 (2015), p. 6.

26 Thurley, 'Disappearing Sounds', p. 18.

27 Quator Bozzini, Jürg Frey: Streichquartett II, online audio recording, Soundcloud (2019) https://soundcloud.com/quatuor-bozzini/j-rg-frey-streichquartett-ii.

28 Anne Leilehua Lanzilotti, Jürg Frey: halftone harmonics, online video recording, Vimeo (2019) https://vimeo.com/348242960.

29 Connell, Masculinities, p. 45. 
Through the application of fragile timbres, Wandelweiser music requires interpreters to interrogate their tiniest motions, often reacting to production methods that are in themselves precarious, to generate sounds that are timbrally unstable and prone to collapse. Analogously, hegemonic masculinity frequently encourages the mistreatment of mens' bodies, through activities such as binge drinking or excessive physical exercise, but perhaps a closer analogue can be found in Connell's note that some athletes' bodies are 'virtually assaulted in the name of masculinity and achievement ${ }^{30}$ Again, it is important to recognise that the bodies so treated need not be male ones: masculinity arguably brings about violence against all bodies.

The physical tension which is required to sustain the performance of fragile timbres reaches towards this motion of offering one's body to hegemonic masculinity: focusing on minuscule movements is laborious and, without caution, approaches an act of violence. Indeed, Morton Feldman's String Quartet No. 2 (1983), an important precursor for Wandelweiser concerns, not least in duration (it lasts six hours or so) and the fragility of timbres, requires performers to undertake extensive changes to their learned, embodied playing technique to avoid the actual physical damage which would result if they were to play these sounds for that long 'normally'. ${ }^{31}$ Edwards notes that the meaning(fullness) of violence is dependent on context. For example, demolishing one's own property ahead of renovation is very different from vandalising someone else's in the name of revenge. ${ }^{32}$ Indeed, focusing on the instability of minute physical movements is not necessarily violent: mindful practices, such as tai chi, use this sort of attentiveness as a tool for relaxation or (personal) exploration. However, in the context of Wandelweiser timbres, mindlessness becomes indistinguishable from physical discomfort and exploitation: the fragile timbres that one hears are the product of physical straining. Wandelweiser composers dominate the performer's body through means which approach violence, thus exercising their hegemonic position through the lens of fragility.

I think I can achieve this sense of 'focus deteriorating the very thing it is focusing on' through marrying notational styles. Fragments of traditional staves will offer points of perceived stability that lead into graphic sections in which the performers are required to 'move towards each other's sounds' whilst never arriving there. By perceived stability, I intend to write actions that are fragile, if not impossible to perform, and always at an excruciatingly, if not impossibly, quiet dynamic. These graphic sections will contain fracturing lines that almost weave in and out of each other overlaid with virtually illegible text - they will be used as prompts for this 'improvisatory deterioration' rather than firm guides. The text and graphics may work to contradict each other. At points, I may obscure the entire score with text or paintings, similar to the graphics between the fragments - hopefully there will be an ambiguity within the notation, putting the performance at risk of totally disintegrating.

As mentioned, this evasive balance is also found within the listening experience of Wandelweiser music. Frey's half-harmonic technique produces a sound that contains pitch material from both stopped notes, blurred by ephemeral overtones, whilst operating around the centre of the sound/noise axis; the detail is both muted and deceptive. ${ }^{33}$ As Thurley notes, when experiencing quiet music listeners must sustain

30 Connell, Masculinities, p. 58.

31 Clark Lunberry, 'Departing Landscapes: Morton Feldman's String Quartet II and Triadic Memories', SubStance, 110/35 (2006), p. 19.

32 Edwards, Cultures of Masculinity, p. 45.

33 Kaija Saariaho, 'Timbre and Harmony: Interpolations of Timbral Structures', Contemporary Music Review, $2 / 1$ (1987), p. 130. 
their focus; for if this falters, even for a moment, they are 'forced outside of the music' and the work returns behind a veil of quietness. ${ }^{34}$ This aural strain not only cultivates a tension within the listener but plays on what Don Ihde refers to as the listener's 'auditory imagination' (essentially, how music might highlight the fallibility of listening), through emulating or pointing towards other sounds, such as those of the environment in the case of Wandelweiser music. ${ }^{35}$ To make a distinction, the aural marathon of Feldman's String Quartet No. 2 allows listeners to drift in and out of focus. However, attention appears to matter to Wandelweiser composers, as a tool of controlling musical experience.

As a consequence of its timbral fragility, the listener must work to grasp the music of the Wandelweiser collective, modeling the 'production relations' found in Connell's work. She states that, for example, the disproportionate accumulation of wealth by men is no statistical accident but a result of the 'productive arena' of masculinity; she goes on to suggest that the circulation of other forms of capital also maintains the dominant position of masculinity. ${ }^{36}$ The affectively reticent tones produced through the lens of fragility require listeners to labour through their ears to accrue some sort of understanding, or 'cultural capital', of these delicate musics. ${ }^{37}$ This precarious listening experience of intense focus and self-doubt works to propagate the Wandelwesier composers' dominance over the listener, mirroring the sorts of relations found in Connell's masculinities.

Although the example of Frey's half-harmonics is particularly fragile in both the production and sonic result, the same sense of timbral instability and subsequent masculine social ordering are found within Wandelweiser works that employ more traditional performance techniques. The tones within Pisaro's Ascending Series (2.1) maintain a quiet dynamic and sit precariously against the ambience of the environment, requiring restraint from the performer to produce sounds that hold the attention of the listener.

\section{Openness of Scores}

Wandelweiser scores often appear to be more a blueprint of the work than complete instructions for the finished product. The two previously discussed works are open to different degrees and invite creative interpretations. Pisaro's Ascending Series (2.1) presents ambiguous durations and requires consideration of the performance's location and/or the production of field recordings. This relocation of agency allows for a wide range of realisations: the rendition performed by and released through the collective contains rather busy ambient sounds, which is not typical of Wandelweiser works more generally. ${ }^{38}$ Frey's Streichquartett II is far more prescriptive but, in spite of Frey's precise vision documented in the instructional video, the brevity of the instructions for the half-harmonic technique and vague glissandi

34 Thurley, 'Disappearing Sounds', p. 18.

35 Don Ihde, Listening and Voice: Phenomenologies of Sound (Albany: SUNY Press, 2012), p. 132.

36 Connell, Masculinities, p. 74

37 Pierre Bourdieu, 'The Forms of Capital', in Handbook of Theory of Research for the Sociology of Education, ed. by J. E. Richardson, trans. by Richard Nice (Westport: Greenwood, 1986), pp. 241-58.

38 Daniel Jones, Michael Pisaro - - Ascending Series (2.1) (To Joachim Eckl), online video recording, YouTube (23 November 2012) <https://www.youtube.com/watch?v=bPvQqj-e8cU> [accessed 4 August 2020] 
require substantial trial and error from the performer. ${ }^{39}$ Taking it to the extreme, Wandelweiser member Manfred Werder composes works that comprise fragmentary texts: the score for his work $2009^{1}$ consists of just five, seemingly unrelated, words. ${ }^{40}$ This openness forces the creative onus onto the performer, as G. Douglas Barrett asks: 'Just how does one realize a score consisting only of the text, "dost / rue / araucaria / ore / lewfü"? 41

The displacement of authorship from composer to interpreter may at first seem to undermine traditional composer-performer power dynamics, borrowing ideas from Cage. Benjamin Piekut suggests that despite his privileged position as a white and boundlessly creative man, the champion of silence's practice and approach to work forefronts humility and discipline, not typical traits of hegemonic masculinity. ${ }^{42}$ However, Judith Lochhead notes that Cage's invitation to hear sounds in their own right implies a 'mode of a proper hearing' which can similarly be said for the realisation of Wandelweiser works. ${ }^{43}$ This openness should not be confused with that found in works by other composers, such as early Feldman scores in which fermatas indicate that the notated instruction should be sustained for an ambiguous amount of time. ${ }^{44}$ Wandelweiser pieces require creative work from the interpreters, such as preparing field recordings or novel performance spaces, trialing various options of form and performance technique, or, as an extreme example, creating a performance from three words as in Werder's 2005': 'time / place / (sounds) ${ }^{45}$

As is problematic with my previous work, I think the points of stability, the notated fragments, are 'too stable'. They're fragile in an illustrative sense, in that they flutter around the threshold of silence, so do present an 'unstable' sound that is hard to balance in production and often deceives the ears. But I wonder if they could be more ambiguous in their notation, providing contradictions within their instructions. At the same time - something that only recently occurred to me when working with a good friend and excellent pianist - I don't think I want the score to be so impenetrable that it puts off performers and they resent my work or don't want to engage with it. That said, the performers know me and I'm confident that they will commit to something that constantly tries to undermine itself and is relentlessly ambiguous.

In opening the score and attempting to alter the composer-performer hierarchy, a lacuna is left that the interpreter must fill in order to realise the work. Connell notes how masculine social ordering duplicates the power structures that it uses, thus maintaining hegemony; for example, most top government officials are men as the process of recruitment and promotion is gendered. ${ }^{46}$ Interpreters subordinate themselves to the will of the composer by becoming creative agents made in the image of their instructor, thus replicating the model set by the hegemony. As Piekut notes with regard to Cage's music, it is actually the absence of the composer that creates a situation which is markedly Cagean. ${ }^{47}$ The interpreters are left to fill a

39 Jürg Frey, Streichquartett II ([n. pub.]: 1998-2000), p. 1. [Thanks to James Luff for providing the score]

${ }^{40}$ Manfred Werder, found words (2008-), http://found-words.blogspot.com/.

${ }^{41}$ G. Douglas Barrett, 'The Silent Network', p. 464.

42 Benjamin Piekut, 'Sound's Modest Witness: Notes on Cage and Modernism', Contemporary Music Review, 31/1 (2012), p. 6.

43 Judith Lochhead, 'Refiguring the Modernist Program for Hearing: Steve Reich and George Rochberg', in The Pleasure of Modernist Music: Listening, Meaning, Intention, Ideology, ed. by Arved Ashby (Rochester: University of Rochester Press, 2004), p. 330.

44 Alistair Noble, Composing Ambiguity: The Early Music of Morton Feldman (Farnham: Ashgate, 2013), p. 130.

45 Manfred Werder, 2005/1, http://placetime.blogspot.com/.

46 Connell, Masculinities, p. 73.

47 Piekut, 'Sound's Modest Witness', p. 15. 
Cage-sized hole and in Wandelweiser music interpreters are required to replicate the composer's role.

Although many of these scores present several possible realisations, the nebulous performance practice of experimental music and the hidden will of its composers limit feasible options. In his investigation into Cage and Deleuze, Joe Panzner writes that - stemming as far back as the famous anechoic chamber anecdote from 1951 - the performance of Cagean events relies more on invention than direct reproduction: 'we are called to discover new ways of creating difference and new ways of willing this event. ${ }^{48}$ But, in spite of this devaluation of fidelity to the score, there are certain sorts of 'inventions' that Cage has in mind. For example, Martin Iddon and Phillip Thomas have observed Cage's handwritten annotations in the premiere score of Solo for Viola, indicating which pages should be performed, their order, and calculations for the time-space durations in relation to the conductor. ${ }^{49}$ The score is apparently open, suggesting that there is not a 'wrong' or 'right' way to realise them, yet Cage appears to have 'better' and 'worse' ways to 'invent' performances in mind.

Following the collective's grounding in interpretations of Cage, this elusive performance practice is carried forward into Wandelweiser music. Werder's three-word score $2005^{1}$ could denote a vast number of performances or events - what is not encapsulated by 'place / time / (sounds)'? - but there are options which require substantially different amounts of labour and may cover numerous genres. As a far-fetched example, the score alone could denote a performance of folk music in a pub, yet a performance akin to the opening paragraph of this article is far more likely: the openness of Wandelweiser scores is undermined by performance practice and the surreptitious will of the composer. Connell's notion of abstract labour, discussed earlier, argues that working-class men are offered the appearance of free will to travel and labour as they please, but the masculine hegemony ensures these liberties adhere to social expectations and ultimately serve hegemonic masculinity, meaning that their career is highly determined: the particular freedoms available to any given subject position are, in this sense, already set out in advance, such that 'freedom' is always already illusory. ${ }^{50}$ Similarly, knowledge of performance practice and the composers' intentions prevent interpreters of these open Wandelweiser score from being truly creative; they offer the illusion of freedom but only to bolster the composer's dominance.

In navigating the veiled intentions of Wandelweiser composers, violence emerges as a method of reinforcing hegemony. As Edwards notes, 'perpetrating' violence cultivates masculinities, 'whereas suffering violence tends to have a "feminizing" or emasculating effect'. ${ }^{51}$ To borrow from Slavoj Žižek, the violence found in the openness of Wandelweiser scores is not 'subjective', as there is no obviously visible physical violence done to or by the performers, notwithstanding the physical strain described above: this is a strain that - for the success of the music - must not become visible. ${ }^{52}$ Instead these works embody an 'objective' violence that is 'inherent in a system ... the more subtle

\footnotetext{
${ }^{48}$ Joe Panzner, The Process that is the World: Cage/Deleuze/Events/Performances (New York: Bloomsbury, 2015), p. 4.

${ }^{49}$ Martin Iddon and Phillip Thomas, John Cage's Concert for Piano and Orchestra (Oxford: Oxford University Press, 2020), p. 305.

${ }^{50}$ Connell, Masculinities, pp. 95-8.

${ }^{51}$ Edwards, Cultures of Masculinity, p. 61.

52 Slavoj Žižek, Violence (London: Profile, 2009), p. 1.
} 
forms of coercion that sustain relations of domination and exploitation, including the threat of violence. ${ }^{53}$ Under the composer's governance interpreters navigate unclear systems, reliant on their subservience to minimal instructions, some of which may arguably require more work to realise than compose. But performers live in fear of their creative decisions not matching the composer's will; if they do something 'wrong' they risk facing the reaction of a disgruntled or displeased composer, either through Cage-like annotations on scores or through public embarrassment. Although there is no evidence that any Wandelweiser composer has ever given a performer such a dressing down, it hardly matters, because the structural violence is about the potential for a composer to do just that. Indeed, as Edwards notes through his personal avoiding certain locations and activities, often owing to his homosexuality, the threat of violence is violent in and of itself. ${ }^{54}$

\section{Conclusion}

I have deployed Connell's theorisation of masculinity and masculinities to trace an underlying masculinity within the music of the Wandelweiser collective. The use of silences places interpreters into deceiving spaces, in which they are led to believe that they may interpret sounds freely and become authors of their own experience. However, these conceptual non-places are ordered by the composer and this enforces their dominant position in much the same way as with hegemonic masculinity. The fragile timbres utilised by Wandelweiser composers strain both the bodies of the performer and listener: interpreters are invited to view their most minuscule movements under a moving and faltering microscope. This demand of bodily labour is found in parallel ways within the social ordering of masculinity, through the guise of athletes or binge drinkers. The openness of Wandelweiser scores appears to create a displacement of authorship from the composer to the interpreter. However, free will may be exercised but only under the parameters set, either explicitly or implicitly, by the composer.

The work is complete; I just need to draw the piece in neat and send it to the performers. Through utilising graphic notation, this process will produce something different to the drafts - the act of composing, for me, is improvisatory. To be honest, I feel a little unenthusiastic with this work and have already lined up a viola commission, which I'm going to try something a little different for. Lockdown has played with my body image; excessive time spent not doing much and with only a handful of people to frame myself against. I can't tell if it's my body that changes regularly or my perception of it, and that has fuelled anxious moments. This is permeating my thoughts about this upcoming work. I want to create a piece which repeats itself, but it is unclear whether the music itself has changed, the context of it, or the way in which one is invited to listen. I doubt it will quell my worries, yet I still feel compelled to compose it and share it with others.

These three factors deceptively put the interpreter at the mercy of the composer's authority. The apparent restraint and sonic invisibility of Wandelweiser music is not indicative of a 'soft' work, but one that maintains a hold over the interpreter's aural experience, bodily movements, and creative agency. Interpreters must labour, often in surreptitious ways, to understand or realise these scores. In the same way my diary entries, their informal style an apparently novel disruption of more academic writing, actually create a limited interpretive

53 Žižek, Violence, p. 8.

${ }^{54}$ Edwards, Cultures of Masculinity, pp. 62-3. 
frame. These passages are not autonomous: the sorts of understandings that the reader has been invited to make are determined by me, implicating my dominant, masculine position as the author, just as Wandelweiser composers determine the work of their interpreters. 